\title{
ANALISIS PEMANFAATAN DANA CORPORATE SOCIAL RESPONSIBILITY (CSR) DALAM PEMBANGUNAN DI KABUPATEN KUTAI TIMUR (STUDI KASUS KECAMATAN TELUK PANDAN DAN BENGALON)
}

\section{ANALYSIS OF THE USE OF CORPORATE SOCIAL RESPONSIBILITY (CSR) IN DEVELOPMENT IN THE EAST KUTAI (CASE STUDY OF TELUK PANDAN AND BENGALON))}

\author{
Dadang Lesmana, Bagus Rai Wibowo \\ *Badan Penelitian dan Pengembangan Kabupaten Kutai Timur \\ Jl. Parkir Utara, Kawasan Perkantoran Pusat Pemerintah Bukit Pelangi \\ Gedung Serba Guna (GSG) Lantai II Ruang Garu \\ Email: dadanglesmana89@gmail.com
}

Diterima: 12 Mei 2021; Direvisi: 15 Juli 2021; Disetujui: 19 Juli 2021

\begin{abstract}
ABSTRAK
Dalam pembangunan Kabupaten Kutai Timur, perusahaan juga terlibat untuk membantu pemerintah melalui Dana Corporate Social Responsibility (CSR). Akan tetapi, dengan besar bantuan perusahaan yang dimiliki, pembangunan Kutai Timur khususnya perdesaan masih belum optimal. Penelitian ini bertujuan menganalisis pemanfaatan dana yang dilakukan oleh penerima bantuan dari perusahaan dalam bentuk CSR dalam pembangunan di kabupaten kutai timur. Penelitian ini menggunakan metode deskriptif kualitatif dengan mengunakan analisis SWOT. Hasil penelitian ini menunjukkan beberapa faktor yang menjadi potensi yaitu keterbukaan perusahaan dalam menyalurkan dana CSR, dukungan pemerintah daerah dan kecamatan, adanya peraturan yang melindungi masyarakat dalam menggunakan dana CSR. Di sisi lain, faktor yang menjadi masalah yaitu kapasitas Masyarakat Desa dalam membuat pengajuan, perencanaan, pengadministrasian, serta pengelolaan bantuan yang masih rendah, kapasitas pendamping juga masih rendah, serta sering terjadi misskomunikasi antara masyarakat dengan perusahaan. Adapun strategi yang dihasilkan menggunakan SWOT adalah Melakukan peningkatan pemanfaatan pengetahuan dan informasi yang dimiliki serta dukungan pemerintah untuk menyerap segala bentuk bantuan dari pihak swasta. Mengoptimalkan koordinasi melalui musyawarah penentuan usulan bersama kelompok usaha. Meningkatkan kapasitas masyarakat desa dalam hal perencanaan, administrasi keuangan, penyusunan proposal dan pengelolaan barang. Memanfaatkan hasil evaluasi yang telah dilakukan sebagai acuan untuk menyusun perencanaan. Pemanfaatan dana dari pihak swasta menjadi kunci dalam pemerataan pembangunan saat ini dimana pihak swasta menjadi sebuah pondasi lewat salah satu sumber dana yang dapat dimanfaatkan. Kesimpulannya Masih rendahnya kapasitas SDM yang menjadi faktor utama kelemahan dalam memanfaatkan dana bantuan dari perusahaan, sedangkan dukungan dari perusahaan sangat tinggi untuk pembangunan kabupaten kutai timur, Masih rendahnya komunikasi antara perusahaan dan pemerintah yang menjadi kendala utama dalam memanfaatkan dana bantuan dari perusahaan. Disarankan dilakukannya pendampingan yang lebih dari pihak pemerintah daerah maupun forum MSH CSR Daerah dalam membantu mendukung dan memfasilitasi penyerapan Dana yang bersumber dari Pihak swasta. Berikutnya perlu adanya transparansi dalam penyerapan dan penyaluran Dana yang bersumber dari pihak swasta agar dapat termonitor dengan baik oleh masyarakat.
\end{abstract}

Kata kunci: Pemanfaatan Dana, CSR, Pembangunan, Desa

\section{ABSTRACT}

In the development of East Kutai Regency, the company is also involved in helping the government through the Corporate Social Responsibility (CSR) Fund. However, with the company's large assistance, the development of East Kutai, especially in rural areas, is still not optimal. This study 
aims to analyze the use of funds made by recipients of assistance from companies in the form of CSR in development in East Kutai Regency. This study uses a qualitative descriptive method using SWOT analysis. The results of this study indicate several factors that have potential, namely the company's openness in distributing CSR funds, support from local and sub-district governments, the existence of regulations that protect the community in using CSR funds. On the other hand, the problematic factors are the capacity of the Village Community in making proposals, planning, administration, and management of assistance which is still low, the capacity of assistants is also still low, and frequent miscommunication between the community and the company. The resulting strategy using SWOT is to increase the use of knowledge and information possessed as well as government support to absorb all forms of assistance from the private sector. Optimizing coordination through deliberation to determine proposals with business groups. Increase the capacity of village communities in terms of planning, financial administration, preparation of proposals and management of goods. Utilize the results of the evaluation that has been carried out as a reference for planning. Utilization of funds from the private sector is the key to equitable development at this time where the private sector is a foundation through one of the sources of funds that can be utilized. In conclusion, the low capacity of human resources is the main factor of weakness in utilizing aid funds from companies, while the support from companies is very high for the development of the East Kutai Regency. The low communication between companies and the government is the main obstacle in utilizing aid funds from companies. It is recommended that more assistance from the local government and the Regional CSR MSH forum be carried out in helping to support and facilitate the absorption of funds sourced from private parties. Next, there is a need for transparency in the absorption and distribution of funds sourced from the private sector so that they can be properly monitored by the public.

Keywords: Utilization of Funds, CSR, Development, Village

\section{PENDAHULUAN}

Pembangunan desa bertujuan untuk meningkatkan kualitas hidup manusia serta penanggulangan kemiskinan, melalui penyediaan pemenuhan kebutuhan dasar, pembangunan sarana dan prasarana, pengembangan potensi ekonomi lokal, serta pemanfaatan sumber daya alam dan lingkungan secara berkelanjutan, dengan mengedepankan kebersamaan, kekeluargaan, dan kegotongroyongan. Namun demikian, banyak wilayah pedesaan di banyak negara berkembang mempunyai lingkungan kelembagaan yang lemah, keterbatasan ketersediaan informasi, biaya koordinasi yang tinggi dan risiko tinggi (Dorward et al., 2003). Selain itu, banyak daerah terpencil, menghadapi masalah transportasi, fasilitas logistik, dan jaringan telekomunikasi yang kurang memadai. Keterbatasan infrastruktur fisik secara signifikan meningkatkan biaya transaksi dan menjadi kendala akses ke pelayanan publik (pendidikan, kesehatan, akses informasi dan bantuan inovasi teknis) dan kegiatan ekonomi (Barrett, 2008).

Adapun pembiayaan pembangunan desa di Kabupaten Kutai Timur yang sudah ada sebelumnya antara lain bersumber dari :

1. Anggaran Pendapatan dan Belanja Negara (APBN) yaitu Dana Desa (DD).

2. Anggaran Pendapatan dan Belanja Daerah (APBD) Provinsi Kalimantan Timur yaitu tambahan DD.

3. Anggaran Pendapatan dan Belanja Daerah (APBD) Kabupaten Kutai Timur yaitu Alokasi Dana Desa.

4. Dana yang bersumber dari Penghasilan Asli Daerah (PADES).

5. Dana Pemberdayaan masyarakat dari pihak swasta atau perusahaan seperti Dana Coorporate Social Responbility (CSR)

Kemudian keterlibatan perusahaan dalam pembangunan desa tertuang dalan Undang undang Nomor 40 Tahun 2007 tentang Perseroan Terbatas (UU PT) pasal 74 ayat 1,2,3 dan 4 yang berbunyi "setiap perseroan yang menjalankan kegiatan usahanya dibidang dan/atau berkaitan dengan segala sumber daya alam wajib melaksanakan tanggung jawab sosial dan lingkungan yang pelaksanaannya dilakukan dengan memperhatikan kepatutan dan kewajaran”. 
Maka dalam hal ini perusahaan wajib melakukan kegiatan berupa Coorporate Social Responsibility (CSR) dan Community Development ke dalam bentuk dana maupun program yang telah mereka tetapkan tiap tahunnya. Selanjutnya Peraturan tentang CSR di kabupaten kutai timur tertuang dalam Peraturan Daerah Kabupaten Kutai Nomor 1 Tahun 2017 Tentang Tanggung Jawab Sosial dan Lingkungan Perusahaan.

Dengan demikian, pemerintah dalam mendukung pembangunan desa sangat besar terbukti dari dana desa dan alokasi dana desa yang besar. Kemudian dari pihak swasta juga turut andil dalam membangun desa dalam bentuk CSR dan Community Development. Akan tetapi, dengan dana besar yang diberikan oleh berbagai pihak tersebut, khususnya penyerapan dana dari pihak swasta yang dilakukan oleh desa masih belum optimal sehingga dampak yang dilaksanakan oleh desa masih belum maksimal.

Maka penelitian ini bertujuan menganalisis pemanfaatan dana yang dilakukan oleh penerima bantuan dari perusahaan dalam bentuk CSR dalam pembangunan di kabupaten kutai timur.

\section{TINJAUAN PUSTAKA}

Menurut Handjaja (2013:1) Corporate Social Responsibility atau yang lebih dikenal dengan CSR merupakan sebuah komitmen dari suatu perusahaan untuk memberikan kontribusi yang lebih pada masyarakat, baik melalui tindakan sosial maupun tanggung jawab lingkungan. Kemudian menurut Herman (2018) menyatakan bahwa program CSR ini merupakan kegiatan dalam bentuk sosial dan lingkungan yang ditujukan kepada masyarakat yang ada disekitar perusahaan maupun masyarakat secara umumnya.

Selanjutnya menurut Martin et al (2017) mengatakan bahwa CSR merupakan suatu kegiatan dalam rangka memperkuat kemampuan perusahaan untuk beradaptasi dengan lingkungannya, komunitas dan stakeholder yang terkait dengannya, baik lokal, nasioal, maupun global. Di dalam pengimplementasiaannya, diharapakan agar unsur-unsur perusahaan, pemerintah dan masyarakat saling berinteraksi dan mendukung, supaya CSR dapat diwujudkan secara komprehensif, sehingga dalam pengambilan keputusan, menjalankan keputusan, dan pertanggungjawabannya dapat dilaksanakan bersama.

Berdasarkan Peraturan Daerah Kabupaten Kutai Nomor 1 Tahun 2017 Tentang Tanggung Jawab Sosial dan Lingkungan Perusahaan menjelaskan bahwa Tanggung Jawab Sosial dan Lingkungan yang disingkat TJSL adalah komitmen perusahaan untuk berperan serta dalam pembangunan ekonomi berkelanjutan guna meningkatkan kualitas kehidupan dan lingkungan yang bermanfaat, baik bagi perseroan sendiri, komunitas setempat, maupun masyarakat pada umumnya.

Kemudian peraturan tersebut menjelaskan ada beberapa bentuk program yang dapat dilakukan perusahaan di kutai timur dalam menjalankan TJSL tersebut, yaitu Bina Lingkungan dan sosial , Kemitraan usaha mikro dan koperasi, Program bantuan langsung pada masyarakat, Program pembangunan sarana dan prasarana fasilitas umum masyarakat, Program bantuan sosial dan lingkungan. Selanjutnya masyarakat dapat mengajukan bantuan kepada perusahaan sesuai dengan peraturan tersebut untuk melakukan pembangunan di wilayah tersebut.

Berdasarkan Permendagri nomor 113 tahun 2014 tentang pengelolaan keuangan desa pasal 10 dan 11 menjelaskan bahwa CSR tersebut termasuk dalam kategori pendapatan lain desa yang sah. Hal ini menandakan bahwa CSR turut andil dalam melakukan suatu pembangunan baik di daerah tersebut. Sehingga masyarakat diperbolehkan memanfaatkan dana bantuan yang disediakan oleh perusahaan untuk melakukan pembangunan.

\section{METODE}


Pada penelitian ini dilakukan pada bulan Mei- Juli 2020. Penelitian ini berfokus pada 2 perusahaan besar yang rutin melakukan program CSR yaitu PT. Indominco Mandiri di Kecamatan Teluk Pandan dan PT. Kaltim Prima Coal di Kecamatan Bengalon.

Penelitian menggunakan data primer dan sekunder. Teknik pengumpulan Data primer melalui survei dengan wawancara dan kuesioner kepada responden yang mewakili elemen masyarakat. Tehnik pengumpulan Data sekunder melalui studi dokumentasi . Kemudian dalam melakukan pembobotan dan rating di pilih responden yang memiliki pengalaman dan pengetahuan terkait dengan penelitian ini.

Pendekatan dalam penelitian ini yaitu metode metode deskriptif kualitatif yaitu metode penelitian yang berlandaskan pada filsafat postpositivisme yang biasanya digunakan untuk meneliti kondisi objek yang alamiah dimana peneliti menjadi intrumen kunci (Sugiyono,2008:15). Adapun analisis yang digunakan adalah analisis SWOT.

Menurut Rangkuti (2009), analisis SWOT adalah identifikasi berbagai faktor secara sistematis untuk merumuskan strategi perusahaan atau organisasi. Analisa SWOT dilakukan dengan mengidentifikasi faktor kekuatan (Strengths), kelemahan (Weaknesses), peluang (Opportunities) dan ancaman (Threat) yang kemudian akhirnya membentuk akronim SWOT. Analisis SWOT menampilkan informasi bagaimana melihat posisi sumber daya dan kemampuan suatu organisasi terhadap kondisi lingkungan/eksternal. Kekuatan dan kelemahan merupakan faktor internal yang dapat dikendalikan sedangkan peluang dan ancaman merupakan faktor eksternal yang tidak dapat dikendalikan. Hasil dari identifikasi keempat faktor tersebut akan digunakan untuk merencanakan strategi apa yang harus dilakukan agar tujuan dari organisasi dapat tercapai. Strategi tersebut dapat diterapkan dengan menyusun faktor-faktor tersebut dalam sebuat matrik SWOT sehingga akan dihasilkan strategi SO, ST, WO dan WT.

\section{HASIL DAN PEMBAHASAN}

Berdasarkan Permendagri no 113 th. 2014 tentang pengelolaan keuangan desa memberikan batasan bahwasanya dana-dana yang bisa di akses oleh desa menurut Pasal 9, 10 dan 11 adalah sebagai berikut:
A. Pendapatan Asli Desa (PADes)
B. Dana Desa (DD)
C. ALokasi Dana Desa (ADD)
D. Bankeu APBD Provinsi
E. Bankeu APBD Kabupaten/Kota
F. Hibah dan sumbangan pihak ke-3 yang tidak mengikat
G. Bantuan dari Perusahaan
H. Hasil Kerja sama dari Pihak ke-3
I. Lain-lain pendapatan Desa yang Sah.

Dari hasil observasi pada lokasi penelitian di dua kecamatan (Teluk Pandan dan Bengalon) ditemukan bahwa dana yang rutin di terima oleh desa tiap tahunnya adalah Pendapatan Asli Desa (PADes), Dana Desa (DD), Alokasi Dana Desa (ADD) serta Bantuan dari Perusahaan yang berbentuk Community Social Responsibility (CSR). Sedangkan bantuan keuangan dari Kabupaten dan Provinsi masih belum rutin di terima oleh desa.

Berdasarkan Gambar 1, bahwa dana bantuan yang di berikan oleh salah satu perusahaan di kutai timur prioritas masih dalam program infrastruktur, kemudian pelestarian lingkungan,sosial budaya, pendidikan, pekerjaan, kesehatan, komunitas dan ekonomi . Kemudian program yang dilakukan oleh pihak swasta tersebut sesuai dengan Peraturan Daerah Kutai Timur Nomor 1 Tahun 2017 tentang Tanggung Jawab Sosial dan Lingkungan Perusahaan 
dan Peraturan Bupati Kutai Timur Nomor 42 tahun 2017 tentang Tanggung Jawab Sosial dan Lingkungan, dimana dalam peraturan tersebut ada 5 program yang di prioritas yaitu Bina Lingkungan dan sosial , Kemitraan usaha mikro dan koperasi, Program bantuan langsung pada masyarakat, Program pembangunan sarana dan prasarana fasilitas umum masyarakat, Program bantuan sosial dan lingkungan.

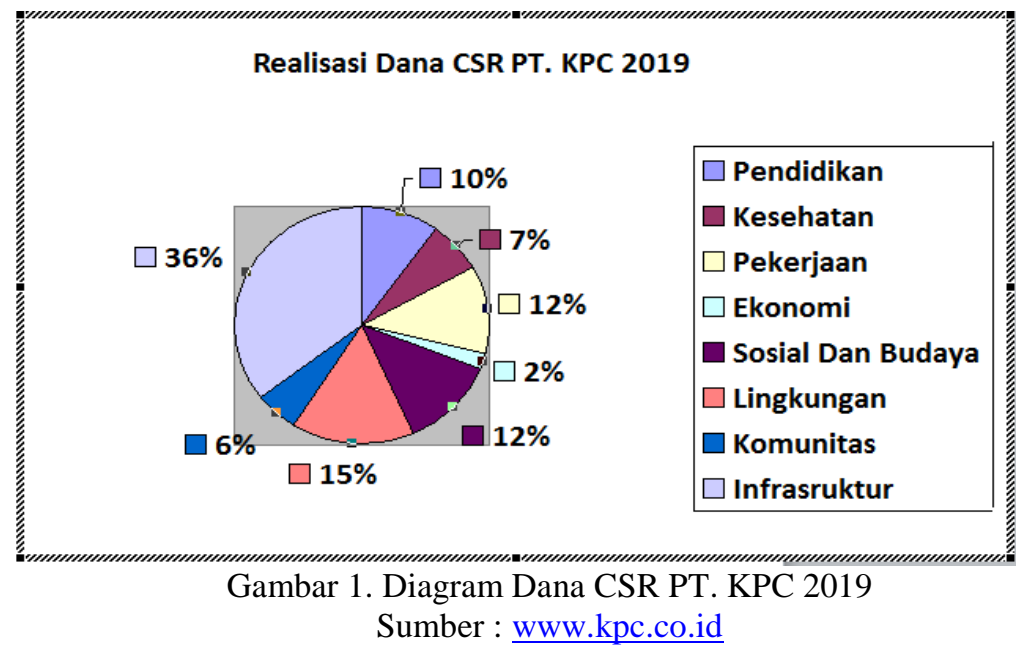

Kemudian, berdasarkan hasil observasi dan wawancara, ada beberapa faktor yang menjadi potensi dan kendala dalam pemanfaatan dana CSR, antara lain

Faktor internal dalam pemanfaatan dana pembangunan dari pihak swasta terbagi menjadi dua, antara lain:

\section{Strength (kekuatan)}

Melalui pengumpulan data terhadap responden di dua lokasi penelitian, dapat diidentifikasikan kekuatan yang dimiliki, antara lain :

a. Pengetahuan tentang Dana yang bisa dimanfaatakn

Masyarakat sudah banyak mengetahui tentang dana apa saja yang dapat mereka manfaatkan untuk pembangunan desa itu sendiri baik dari pihak pemerintah maupun dari pihak swasta

b. Memiliki Motivasi Tinggi dalam membangun desanya sendiri

c. Memiliki Inisiatif Tinggi dalam mencari dana

Masyarakat sering berinisiatif langsung mencari dana ke perusahaan tanpa melalui pemerintah kecamatan.

d. Kelompok Usaha yang Beragam

Masyarakat juga membentuk suatu forum untuk merencanakan apa yang mereka butuhkan yang kemudian disampaikan kepada pihak pemerintah kecamatan dan pihak swasta.

\section{Weakness (kelemahan)}

Melalui pengumpulan data terhadap responden di dua lokasi penelitian, dapat diidentifikasikan kelemahan yang dimiliki, antara lain :

a. Kapasitas SDM dalam penyusunan perencanaan/program pembanggunan desa masih kurang

Masyarakat masih kurang dalam penyusunan rencana/program untuk diusulkan ke dalam RKPDes.

b. Kurang mampu dalam membuat proposal yang baik dan benar masyarakat dalam mengajukan bantuan, cenderung usulan yang diajukan belum terencana dengan baik

c. Kurang mampu dalam pengadministrasian, pengelolaan barang dan keuangan 
Setelah masyarakat mendapatkan bantuan barang/uang, kemudian masyarakat belum mampu membuat administrasi, pengelolaan yang barang, dan keuangan.

d. Kurang mengetahui tata cara evaluasi dan membuat laporan yang baik

e. Kapasitas Pendamping Desa masih kurang

Kapasitas pendamping desa masih kurang dalam melakukan pendampingan kepada masyarakat dalam membangun desanya.

Faktor eksternal dalam pemanfaatan dana pembangunan dari pihak swasta terbagi menjadi dua, antara lain:

\section{Opportunity (peluang)}

Melalui pengumpulan data terhadap responden di dua lokasi penelitian, dapat diidentifikasikan peluang yang dimiliki, antara lain :

a. Tersedianya bantuan yang besar dari pihak swasta

Sebagai bentuk pertanggung jawaban swasta/perusahaan untuk membantu masyarakat sekitar melalui Tanggung jawab sosial dan lingkungan, maka pihak swasta/perusahaan memiliki banyak sekali program bantuan yang diediakan untuk masyarakat.

b. Tersedianya informasi tentang bantuan yang dapat dimanfaatkan

Dalam rangka untuk melaksanakan dan menyalurkan tanggung jawab sosial dan lingkungannya, pihak swasata/perusahaan selalu memberikan informasi mengenai jenis bantuan apa saja yang dapat di akses dan di manfaatkan oleh masyarakat melalui forum musyawarah terbuka

c. Dukungan dari pemerintah daerah

Dengan dibentuknya Forum MSH CSR tingkat Daerah, pemerintah daerah telah melakukan upaya untuk mendampingi dan mendukung masyarakat untuk dapat menyerap bantuan dari swasta/perusahaan semaksimal mungkin dan tepat sasaran

d. Adanya Peraturang Daerah dan Peraturan Bupati tentang Tanggung Jawab Sosial dan Lingkungan

Adanya Peraturan Daerah Kutai Timur nomor 1 tahun 2017 tentang Tanggung Jawab Sosial dan Lingkungan Perusahaan dan Peraturan Bupati nomor 42 tahun 2017 tentang Tanggung Jawab Sosial (TJSL) dmaksudkan untuk membantu mengendalikan bantuan swasta/perusahaan dalam program tanggung jawab sosial dan lingkungan yang dapat dimanfaatkan oleh masyarakat agar tepat sasaran dan sesuai dengan kebutuhan pembangunan dan peningkatan perekonomian masyarakat

\section{Threats (ancaman)}

Melalui pengumpulan data terhadap responden di dua lokasi penelitian, dapat diidentifikasikan peluang yang dimiliki, antara lain :

a. Bantuan tidak sesuai RKPDesa

Sebagian besar masyarakat yang mengajukan bantuan langsung ke perusahaan, tetapi tidak berdasarkan RKPDesa.

b. Belum selarasnya antara perencanaan desa dan perencanaan swasta/perusahaan

Pihak swasta dalam pembangunan desa memiliki perencanaan tersendiri, sedangkan desa juga memiliki perencanaan sendiri. kemudian pemerintah desa berharap pihak swasta berkontribusi dalam perencanaan desa.

c. Terdapat konflik kepentingan masyarakat dan pemerintah desa dalam mengajukan program

d. Hasil Evaluasi oleh tim monitoring dan evaluasi belum dijadikan pedoman perencanaan desa selanjutnya

e. Terjadi miskomunikasi antara masyarakat dengan perusahaan 
Analisis Pemanfaatan Dana Corporate Social Responsibility (CSR) Dalam Pembangunan di Kabupaten Kutai

Timur (Studi Kasus Kecamatan Teluk Pandan dan Bengalon)

Dadang Lesmana, Bagus Rai Wibowo

Sering terjadi miskomunikasi antara masyarakat dan perusahaan dalam mengajukan bantuannya.

Berdasarkan uraian diatas, maka selanjutnya dilakukan analisis SWOT dengan mengawinkan variabel ke dalam 4 kuadran untuk menghasilkan strategi yang tepat. Berikut hasil analisis SWOT pada tabel 1.

Tabel 1. Analisis SWOT

\begin{tabular}{|c|c|c|}
\hline $\mathbf{E}$ & $\begin{array}{l}\text { KEKUATAN (S) } \\
\text { 1. Pengetahuan tentang dana yang bisa } \\
\text { dimanfaatkan } \\
\text { 2. Memiliki motivasi tinggi } \\
\text { 3. Memiliki inisiatif tinggi dalam mencari dana } \\
\text { 4. Kelompok usaha yang beragam }\end{array}$ & $\begin{array}{l}\text { KELEMAHAN (W) } \\
\text { 1. Kapasitas SDM dalam Penyusunan } \\
\text { rencana/program masih kurang } \\
\text { 2. Kurang mampu membuat proposal } \\
\text { yang baik dan benar } \\
\text { 3. Kurang mampu pengadministrasian } \\
\text { dalam pengelolaan barang dan } \\
\text { keuangan } \\
\text { 4. Kurang mengetahui tata cara } \\
\text { evaluasi dan membuat laporan yang } \\
\text { baik } \\
\text { 5apasitas Pendamping desa masih } \\
\text { kurang }\end{array}$ \\
\hline $\begin{array}{l}\text { PELUANG }(\mathrm{O}) \\
\text { 1. Tersedianya bantuan yang } \\
\text { besar dari pihak swasta } \\
\text { 2. Tersedianya informasi tentang } \\
\text { bantuan yang dimanfaatkan } \\
\text { 3. Dukungan dari pemerintah } \\
\text { 4. Adanya Peraturan Daerah dan } \\
\text { Peraturan Daerah tentang TJSL }\end{array}$ & $\begin{array}{l}\text { STRATEGI (S-O) } \\
\text { 1. S1 - O1, O2 Manfaatkan pengetahuan dan } \\
\text { informasi utnuk menyerap bantuan secara } \\
\text { optimal } \\
\text { 2. S1 - O1, O3 Manfaatakan pengetahuan dan } \\
\text { dukungan dari pemerintah daerah untuk } \\
\text { menyerap bantuan dari pihak } \\
\text { swasta/perusahaan sebesar-besarnya } \\
\text { 3. S2,S3,S4 - O1 Manfaatkan motivasi, inisiatif } \\
\text { dan keberagaman untuk mendapatkan } \\
\text { bantuan dari pihak swasta sebesar mungkin }\end{array}$ & $\begin{array}{l}\text { STRATEGI ( W-O) } \\
\text { 1. W1,W3, W5 - O1,O3 Tingkatkan } \\
\text { kapasitas masyarakat dalam } \\
\text { perencanaan, administrasi } \\
\text { keuangan, dan pengelolaan barang } \\
\text { 2. W4, W5 -O4 Tingkatkan kapasitas } \\
\text { masyarakat dalam pengendalian dan } \\
\text { evaluasi } \\
\text { 3. W2, W5 - O1, O3 Manfaatkan } \\
\text { dukungan dari pemerintah daerah } \\
\text { dan pihak swasta/perusahaan untuk } \\
\text { meningkatkan kemampuan } \\
\text { masyarakat dalam membuat } \\
\text { proposal yang baik dan benar }\end{array}$ \\
\hline $\begin{array}{l}\text { ANCAMAN (T) } \\
\text { 1. Bantuan tidak sesuai RKPDesa } \\
\text { 2. } \begin{array}{l}\text { Belum selarasnya antara } \\
\text { perencanaan desa dan } \\
\text { perencanaan } \\
\text { swasta/perusahaan }\end{array} \\
\text { 3. Terdapat konflik kepentingan } \\
\text { masyarakat dan pemerintah } \\
\text { desa dalam mengajukan } \\
\text { program } \\
\text { 4. Hasil Evaluasi oleh tim } \\
\text { MONEV belum dijadikan } \\
\text { pedoman perencanaan desa } \\
\text { selanjutnya } \\
\text { Terjadi miskomunikasi antara } \\
\text { masyarakat dan perusahaan }\end{array}$ & $\begin{array}{l}\text { STRATEGI (S-T) } \\
\text { 1. } \\
\text { S2 - T4 Gunakan hasil evaluasi pada } \\
\text { perencanaan desa selanjutnya } \\
\text { 2. } \mathrm{S} 1, \mathrm{~S} 3 \text { - T1,T3 Optimalkan kesepakatan } \\
\text { masyarakat dalam RKPDes } \\
\text { 3. } \mathrm{S} 4 \text { - T3 Tingkatkan kerja sama antara } \\
\text { pemerintah desa dan kelompok usaha } \\
\text { masyarakat dalam menenntukan program } \\
\text { pembangunan }\end{array}$ & $\begin{array}{l}\text { STRATEGI }(\mathrm{W}-\mathrm{T}) \\
\text { 1. W1 - T2, T5 Tingkatkan } \\
\text { keselarasan perencanaan desa dan } \\
\text { perencanaan swasta/perusahaan } \\
\text { 2. } \mathrm{W} 1 \text { - T1 Tingkatkan kapasitas } \\
\text { masyarakat dalam penyusunan } \\
\text { rencana pembangunan desa untuk } \\
\text { menyerap bantuan sebesar-besarnya } \\
\text { lewat dokumen RKPDes }\end{array}$ \\
\hline
\end{tabular}

Sumber : Data diolah (2019)

Berdasarkan tabel diatas, beberapa strategi-strategi yang dianalisis menggunakan SWOT, antara lain:

\section{Strategi S-O \\ Strategi S-O adalah strategi dengan memaksimalkan kekuatan (S) untuk menangkap Peluang (P).}




\section{S1 - O1, O2 Manfaatkan pengetahuan dan informasi utnuk menyerap bantuan secara optimal}

Masyarakat harus memanfaatkan pengetahuan tentang dana yang dimanfaatkan dan informasi yang tersedia untuk menyerap bantuan yang tersedia oleh pihak swasta.

S1 - O1, O3 Manfaatakan pengetahuan dan dukungan dari pemerintah daerah untuk menyerap bantuan dari pihak swasta/perusahaan sebesar-besarnya

Masyarakat harus mampu memanfaatkan pengetahuan dan memaksimalkan dukungan dari pemerintah daerah agar dapat lebih banyak menyerap bantuan dari swasta/perusahaan dengan tepat.

S2,S3,S4 - O1 Manfaatkan motivasi, inisiatif dan keberagaman kelompok usaha untuk mendapatkan bantuan dari piihak swasta/perusahaan sebesar-besarnya

Masyarakat desa memiliki motivasi yang tinggi untuk membangun desanya, memiliki inisiatif tinggi dalam mencari dana ke pihak swasta serta kelompok usaha yang beragam sehingga perlu dimanfaatkan dengan baik untuk mendapatkan bantuan yang disediakan oleh pihak swasta/perusahaan lewat musyawarah penentuan usulan bantuan desa.

\section{Strategi W-O}

Strategi W-O adalah strategi dengan meminimalkan kelemahan (W) untuk menangkap Peluang $(\mathrm{O})$.

W1,W3 - 01,O3 Tingkatkan kapasitas masyarakat dalam perencanaan, administrasi keuangan, dan pengelolaan barang

Peningkatan kapasitas masyarakat desa dalam melakukan penyusunan rencana/program pembangunan desa, pengadministrasian keuangan serta pengelolaan barang yang di berikan oleh pihak swasta.

W4 -O4 Tingkatkan kapasitas masyarakat dalam pengendalian dan evaluasi

Peningkatan kapasitas masyarakat desa dalam melakukan pengendalian dan evaluasi pada bantuan yang diberikan oleh pihak swasta yang tertuang dalam Peraturan Bupati dan Peraturan Daerah tentang Tanggung Jawab Sosial Lingkungan.

W2 - O1, O3 Manfaatkan dukungan dari pemerintah daerah dan pihak swasta/perusahaan untuk meningkatkan kemampuan masyarakat dalam membuat proposal yang baik dan benar

Pemerintah daerah harus meningkatkan kemampuan masyarakat desa dalam mengajukan permohonan bantuan ke pihak swasta/perusahaan dengan memfasilitasi masyarakat pelatihan penyusunan proposal bantuan.

\section{Strategi S-T}

Strategi S-T adalah strategi dengan memaksimalkan kekuatan (S) dalam menghadapi ancaman $(\mathrm{T})$.

S2 - T4 Gunakan hasil evaluasi pada perencanaan desa selanjutnya

Hasil evaluasi yang telah dilakukan oleh tim monitoring dan evaluasi dijadikan pedoman oleh pemerintah desa dan masyarakat untuk penyusunan perencanaan desa selanjutnya.

\section{S1,S3 - T1,T3 Optimalkan kesepakatan masyarakat dalam RKPDes}

Pemerintah desa harus membentuk kesepakatan dengan masyarakat desa tentang kegiatan prioritas pembangunan yang akan dimasukkan ke dalam RKPDes.

S4 - T3 Tingkatkan kerja sama antara pemerintah desa dan kelompok usaha masyarakat dalam menenntukan program pembangunan

Pemerintah Desa harus membentuk kesepakatan dengan kelompok usaha masyarakat dalam penentuan program pembangunan desa. 
Analisis Pemanfaatan Dana Corporate Social Responsibility (CSR) Dalam Pembangunan di Kabupaten Kutai Timur (Studi Kasus Kecamatan Teluk Pandan dan Bengalon)

Dadang Lesmana, Bagus Rai Wibowo

\section{Strategi W-T}

Strategi W-O adalah strategi dengan meminimalkan kelemahan (W) dalam menghadapi ancaman $(\mathrm{T})$

W1 - T2 Tingkatkan keselarasan perencanaan desa dan perencanaan swasta/perusahaan

Perlu dilakukan koordinasi oleh unsur desa dengan pihak swasta/perusahaan dalam rangka penyusunan perencanaan pembangunan desa

W1 - T1 Tingkatkan kapasitas masyarakat dalam penyusunan rencana pembangunan desa untuk menyerap bantuan sebesar-besarnya lewat dokumen RKPDes

Pemerintah harus meningkatkan kapasitas masyarakat desa dalam menentukan program prioritas pembangunan desa dengan memfasilitasi pelatihan penentuan program prioritas.

\section{KESIMPULAN}

Hasil Penelitian ini dapat dirumuskan kesimpulan sebagai berikut:

1. Sumber-sumber dana pembangunan yang dapat dimanfaatkan oleh desa di Kutai Timur adalah adalah Pendapatan Asli Desa (PADes), Dana Desa (DD), Alokasi Dana Desa (ADD), Bantuan Keuangan Kabupaten, Bantuan Keuangan Provinsi serta Bantuan dari Perusahaan yang berbentuk Community Social Responsibility (CSR).

2. Masih rendahnya kapasitas SDM yang menjadi faktor utama kelemahan dalam memanfaatkan dana bantuan dari perusahaan, sedangkan dukungan dari perusahaan sangat tinggi untuk pembangunan kabupaten kutai timur

3. Masih rendahnya komunikasi antara perusahaan dan pemerintah yang menjadi kendala utama dalam memanfaatkan dana bantuan dari perusahaan.

\section{REKOMENDASI}

Dalam melaksanakan strategi maka dibuatlah sebuah rekomendasi yang disusun secara sistematis berbentuk program dan kegiatan agar dapat tepat sasaran dalam pelaksanaannya yang dapat dijelaskan sebagai berikut;

1. Melakukan peningkatan pemanfaatan pengetahuan dan informasi yang dimiliki desa untuk menyerap segala bentuk bantuan melalui penyusunan program yang baik melalui identifikasi jenis bantuan yang di programkan oleh perusahaan/swasta, penyusunan program kegiatan prioritas desa dan penyusunan proposal yang baik dan benar.

2. Melakukan peningkatan pemanfaatan pengetahuan dan dukungan dari pemerintah daerah untuk menyerap sebesar-besarnya bantuan dari pihak swasta melalui peningkatan kerja sama dengan bentuk memfasilitasi kerja sama antara perusahaan/swasta dengan masyarakat desa.

3. Meningkatkan pemnafaatan sumber daya yang dimiliki oleh desa untuk menyerap bantuan dari perusahaan/swasta dengan mengoptimalkan koordinasi melalui musyawarah penentuan usulan bersama kelompok usaha.

4. Meningkatkan kapasitas masyarakat desa dalam hal perencanaan, administrasi keuangan, penyusunan proposal dan pengelolaan barang melalui pelatihan teknis.

5. Memanfaatkan hasil evaluasi yang telah dilakukan sebagai acuan untuk menyusun rencana yang lebih baik dalam menyerap program bantuan dari perusahaan/swasta kedepannya agar lebih maksimal.

\section{DAFTAR PUSTAKA}

Badan Penelitian dan Pengembangan Sumatera Utara. (2011). Studi Tentang Corporate Social Responsibility (CSR) Badan Usaha Milik Negara (BUMN) yang Ada di Sumatera Utara. 
Handjaja, Gabriela. (2013). Analisis Penerapan Corporate Social Responsibility di Perusahaan Multilevel Marketing PT. Harmoni Dinamik Indonesia. Jurnal Ilmia, 2(2), Surabaya.

Herman. (2018). Manfaat Corporate Social Responsibility oleh Stakeholder Primer dan Sekunder (Studi Kasus Pada PT. Asia Sawit Makmur Jaya Provinsi Riau). Jurnal Ilmiah Manajemen Publik dan Kebijakan Sosial, 2(2), 2018.

Kaltim Prima Coal. (2019). Community Development Implementation Report. Dari https://kpc.co.id/community-development-implementation-report/\#, diakses pada tanggal 23 Februari 2019.

Martin, Rafael. Yadiati, Winwin. Pratam, Arie. (2018). Corporate Social Responsibility Disclosure and Company Financial Performance: Do High and Low Profile Industry Moderate the Result?. Indonesian Journal of Sustainability Accounting and Management, 2018, 2(1), 15-24.

Menteri Dalam Negeri. (2014). Peraturan Menteri Dalam Negeri Nomor 113 Tahun 2014 tentang Pengelolaan Keuangan Desa. Jakarta

Menteri dalam Negeri. (2014). Peraturan Menteri Dalam Negeri Nomor 114 Tahun 2014 tentang Pedoman Pembangunan Desa. Jakarta

Pemerintah Kabupaten Kutai Timur. (2017). Peraturan Daerah Kutai Timur Nomor 1 Tahun 2017 tentang Tanggung Jawab Sosial dan Lingkungan Perusahaan. Kutai Timur

Pemerintah Kabupaten Kutai Timur. (2017). Peraturan Bupati Kutai Timur Nomor 42 tahun 2017 tentang Tanggung Jawab Sosial dan Lingkungan. Kutai Timur

Pemerintah Republik Indonesia. (2012). Peraturan Pemerintah Nomor 47 tahun 2012 tentang Tanggung Jawab Sosial dan Lingkungan Perseroan Terbatas. Jakarta

Rangkuti, Freddy. (2014). ANALISIS SWOT : Tehnik Membedah Kasus Bisnis. PT. Gramedia Pustaka Utama, Jakarta. 